\title{
Paget-Schroetter syndrome in a young fitness enthusiast with a negative D-dimer: highlighting the balance between clinical suspicion and diagnostic modalities
}

\author{
Abrar Gani @ (1) ${ }^{1}$ Georgia Lucas, ${ }^{2,3}$ Jonathan Simon Refson, ${ }^{4}$ Awad El-karim ${ }^{5}$
}

${ }^{1}$ Department of Surgery,

Princess Alexandra Hospital NHS Trust, Harlow, UK

${ }^{2}$ Princess Alexandra Hospital, Princess Alexandra Hospital NHS Trust, Harlow, UK

${ }^{3}$ Department of Paediatrics, North Middlesex University Hospital, London, UK ${ }^{4}$ Department of Vascular Surgery, The Princess Alexandra Hospital, Harlow, UK ${ }^{5}$ Department of Acute Medicine, Princess Alexandra Hospital, Harlow, UK

\section{Correspondence to \\ Dr Abrar Gani;}

abrar.gani1@nhs.net

AG and $G L$ are joint first authors.

Accepted 17 December 2020

Check for updates

(c) BMJ Publishing Group Limited 2021. No commercial re-use. See rights and permissions. Published by BMJ.

To cite: Gani A, Lucas G,
Refson JS, et al. BMJ Case
Rep 2021;14:e240165.
doi:10.1136/bcr-2020-
240165

\section{DESCRIPTION}

A 22-year-old man presented to the emergency department with a 3-week history of spontaneous right arm ache and swelling. He reported that his symptoms were exacerbated by exercise. There was no history of trauma, weight loss or fever. He had no previous medical history. He was a right-handed sportsman playing regular racket sports.

On examination, he had an oedematous right arm with a dusky discolouration (figure 1), with distended neck veins. The right arm had good volume pulses peripherally, with a capillary refill time of $<2 \mathrm{~s}$. Sensory and motor function was preserved with no deficit bilaterally.

Routine baseline serum blood test and haemophilia screen were within normal range. Of note, his D-dimer was not raised at $<150 \mathrm{ng} / \mathrm{mL}$ (normal range $0-230 \mathrm{ng} / \mathrm{mL}$ ). He underwent CT neck/ thorax/abdomen/pelvis with upper limb venogram. This demonstrated no evidence of lymph node enlargement or compressive pathology. Furthermore, the CT revealed good opacification of the neck and thoracic veins with adequate opacification of the arteries. Therefore, it effectively excluded both vascular compression and occlusive insult. In view of the inconclusive serum blood tests and imaging results, we proposed alternative imaging modality. Doppler ultrasound sonography revealed a right distal subclavian vein thrombus with extension into the right brachiocephalic vein.

The patient was discussed in the vascular multidisciplinary meeting to discuss optimal revascularisation options. The joint discussion and case review confirmed the diagnosis of Paget-Schroetter syndrome (PSS). Given the subacute nature of the presentation, neither surgical decompression nor

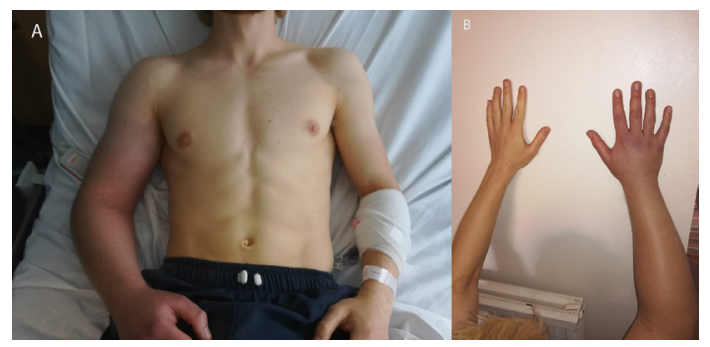

Figure 1 On initial presentation to the hospital. (A) and (B) show significant swelling of the right arm with dusky discolouration.

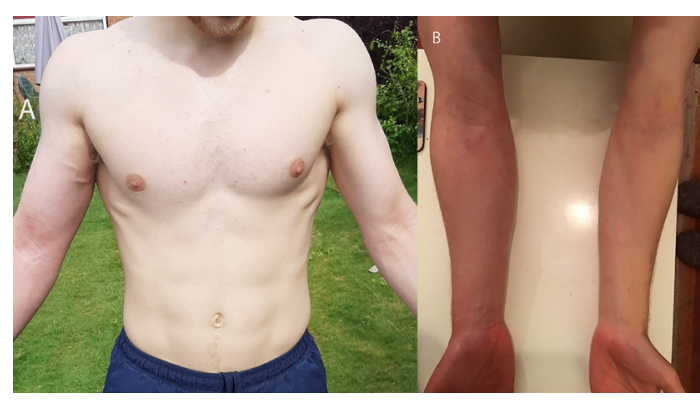

Figure 2 Six months after commencement of anticoagulation. (A) and (B) show minimal swelling of the right arm with mild discolouration.

thrombolysis was deemed appropriate at this stage. Our patient was started and managed conservatively on oral anticoagulation (apixaban).

At 4 weeks follow-up, our patient had significant improvement of his right upper limb oedema and discolouration (figure 2). At this stage, elective surgical decompression was deferred pending further re-evaluation with dedicated imaging. On the second follow-up, 6 months postdischarge, although the patient continued to demonstrate improvement of symptoms, the improvement was insufficient. Our patient was both a competitive badminton player and a swimmer. He found his arms fatigued and oedematous within the early stages of a badminton game. Additionally, the biomechanics during the catch phase rotation in

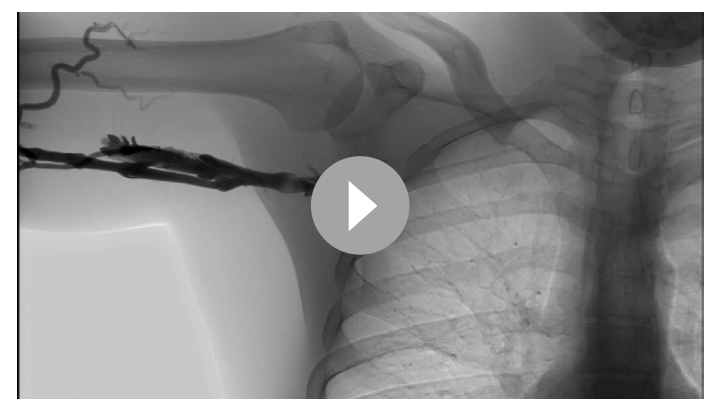

Video 1 Venogram demonstrating numerous venous collaterals in the right shoulder joint, with a short segment chronic occlusion of the right subclavian vein as it crosses the first rib with delayed enhancement and drainage of the right brachiocephalic vein and SVC. 
freestyle swimming resulted in repetitive compression of venous outflow and eventually recurrence of symptoms.

Repeat right upper limb venogram revealed numerous venous collaterals in the right shoulder joint, with a short segment chronic occlusion of the right subclavian vein (video 1 ). Following a multidisciplinary teams discussion, a decision was made to proceed to surgical intervention due to unsatisfactory resolution of symptoms. Our patient underwent a first rib

\section{Patient's perspective}

I would describe the first symptoms as a dull aching in my elbow region, which I would compare to tennis elbow. During the next week, I felt more aching until my whole arm felt extremely heavy and hard to the touch. During the first week where the clot was forming, I also saw the swelling increase. The only other symptom was discolouration which I would describe as 'greyishblue'. I would not say that my arm ever felt painful, but very uncomfortable.

I presented to A\&E and was admitted 3 week after onset of first symptoms. A venogram failed to show the clot, but the clot was found the next day (I was admitted for one night) by means of an ultrasound scan. During this one-night stay in hospital, I would say the symptoms doubled - this includes the swelling, discolouration and feelings of heaviness and hardness. The swelling was so severe that I could not bend my arm at the elbow. By the time I was discharged from hospital 1 day later (with apixaban and a compression sleeve for my arm), the symptoms were at their worst.

I revisited the consultant vascular surgeon after 2 days, and most of the acute swelling and other symptoms had reduced remarkably. After around 1 month of anticoagulation and compression, I was able to resume low intensity exercise such as exercise bike, jogging and other cardio machines. I spent the next 9 months doing lowintensity exercise in this way. I tried to restart other exercises using my arm (including weightlifting, swimming and racket sports), but these caused a small amount of the original symptoms to return. I noticed that these symptoms would disappear within 10 mins of stopping exercise if I held my arm above my head. I believe this is mostly due to the expansion of my collateral veins, which became more visible under my skin around my bicep, shoulder and pectoral muscle as time went on.

About 6 months after developing the clot, I was given a venogram that showed there had been little or no dissolving of the clot, but my collaterals had expanded well. I was not satisfied with this, as I was still getting some symptoms when doing very strenuous exercise involving my arm. Therefore, I requested an operation to improve the flow of blood in my subclavian vein.

On 13 August 2020, I underwent a complete first rib resection and bypass from my subclavian vein to my jugular. The vein was harvested from the saphenous vein. I stayed in hospital for five nights after this. I am now writing this account 2 weeks after the surgery. The pain has now reduced, and I am left with a soreness and stiffness in my shoulder. This will be corrected with the help of physiotherapy over the next couple of months. I have already noticed that the visible collaterals have reduced which I believe indicates a successful bypass. A venogram was conducted during the surgery and showed there was good flow of blood through the bypass.

I hope that in 6 months, the bypass will allow me to resume strenuous upper body exercise without getting any symptoms at all.
Learning points

- Clinical judgement based on clinical assessment is invaluable. Additional investigations should be utilised to support clinical suspicion.

- Paget Shroetter Syndrome is an important differential to remember in young healthy athletic individuals presenting with unilateral swelling

- Treatment of Paget Shroetter syndrome includes pharmacological and percutaneous therapies alongside surgical decompression.

resection with a right subclavian vein bypass using the saphenous as conduit. A combined approach was used due to the extent of proximal occlusion. Initially an infraclavicular approach was used to split pectoralis fibres and expose subclavian vein. Supraclavicular approach was next used to expose internal jugular vein to achieve end to side veno-veno bypass from the patent axillary vein to internal jugular vein. We performed first rib resection to safely tunnel the bypass under the clavicle. Our patient had a good outcome postoperatively and was commenced on oral anticoagulation for a further year to maintain patency of venous graft.

There is limited data in current literature regarding adjunctive therapy postsurgical decompression in PSS. Fairman et al found no benefit for long-term anticoagulation as adjunctive treatment postsurgical decompression. ${ }^{1}$ However, in our case, anticoagulation was continued for an additional year to maintain graft patency.

PSS, also known as effort thrombosis, is a form of upper extremity deep vein thrombosis. Aetiology of PSS is a combination of anatomical abnormalities of the thoracic outlet combined with repetitive movements of the upper limb, resulting in thrombus formation and subsequent venous occlusion. PSS is rare with an incident rate of around 1-2/100 000 population and is more common in patients in their 30 s. PSS is diagnosed using clinical assessment, serum markers and imaging modalities. ${ }^{2}$

Diagnosis of PSS, in this case, was challenging due to a false-negative D-dimer and CT venogram. D-dimer has a high sensitivity of $96 \%$ for venous thromboembolism, however, the false-negative result in our case may be due to the chronicity of the culprit thrombotic event. ${ }^{34} \mathrm{D}$-dimer is also less sensitive in upper extremity deep vein thrombosis (UEDVT). ${ }^{5}$ Diagnosis of PSS in our case was confirmed on doppler USS, which should remain the first-line radiological investigation in suspected PSS. There is a lack of consensus on optimal management for PSS. Management can be conservative or surgical and our case demonstrates both management options and their outcomes. ${ }^{6}$

Contributors To whom it may concern, I would like to declare myself $A G$ and $G L$ as joint first authors. We have equally contributed in the case write-up and image production for this case AE-k was the lead medical consultant who alongside JSR the operating consultant reviewed our submission and provided invaluable advice and support to prepare for submission. Regards, AG.

Funding The authors have not declared a specific grant for this research from any funding agency in the public, commercial or not-for-profit sectors.

Competing interests None declared.

Patient consent for publication Obtained.

Provenance and peer review Not commissioned; externally peer reviewed. 
ORCID iD

Abrar Gani http://orcid.org/0000-0002-6772-3305

\section{REFERENCES}

1 Fairman AS, Fairman RM, Foley PJ, et al. Is routine postoperative anticoagulation necessary in all patients after first rib resection for Paget-Schroetter syndrome? Ann Vasc Surg 2020;69:217-23.

2 Alla VM, Natarajan N, Kaushik M, et al. Paget-schroetter syndrome: review of pathogenesis and treatment of effort thrombosis. West J Emerg Med 2010;11:62 https://pubmed.ncbi.nlm.nih.gov/21079709
3 Stein PD, Hull RD, Patel KC, et al. D-Dimer for the exclusion of acute venous thrombosis and pulmonary embolism: a systematic review. Ann Intern Med 2004;140:589-602.

4 Goldin Y, Pasvolsky O, Rogowski O, et al. The diagnostic yield of D-dimer in relation to time from symptom onset in patients evaluated for venous thromboembolism in the emergency medicine department. J Thromb Thrombolysis 2011;31:1-5.

5 Sartori M, Migliaccio L, Favaretto E, et al. D-Dimer for the diagnosis of upper extremity deep and superficial venous thrombosis. Thromb Res 2015;135:673-8.

6 Urschel HC, Razzuk MA. Paget-Schroetter syndrome: what is the best management? Ann Thorac Surg 2000;69:1663-8.

Copyright 2021 BMJ Publishing Group. All rights reserved. For permission to reuse any of this content visit https://www.bmj.com/company/products-services/rights-and-licensing/permissions/

BMJ Case Report Fellows may re-use this article for personal use and teaching without any further permission.

Become a Fellow of BMJ Case Reports today and you can:

- Submit as many cases as you like

- Enjoy fast sympathetic peer review and rapid publication of accepted articles

- Access all the published articles

Re-use any of the published material for personal use and teaching without further permission

Customer Service

If you have any further queries about your subscription, please contact our customer services team on +44 (0) 2071111105 or via email at support@bmj.com.

Visit casereports.bmj.com for more articles like this and to become a Fellow 